\title{
Analysis of Parathyroid Hormone and Its Fragments in Rat Tissues
}

\section{CHEMICAL IDENTIFICATION AND MICROSCOPICAL LOCALIZATION}

\author{
Pierre D’Amour, Gino V. Segre, Sanford I. Roth, and John T. Potts, Jr., \\ Department of Medicine and Department of Pathology, Harvard Medical School, \\ and Endocrine Unit and Department of Pathology, Massachusetts General \\ Hospital, Boston, Massachusetts 02114
}

\begin{abstract}
A B S T RACT After intravenous injection of $\left[{ }^{125} \mathrm{I}\right]-$ iodo-parathyroid hormone in the rat, uptake of the hormone was greatest in the liver and kidneys. Uptake was rapid, reaching a maximal concentration by 4 and 8 min, respectively. Extracts, prepared from both these organs at intervals soon after the injection of intact hormone, showed three main radioactive peaks when samples were subjected to gel filtration under proteindenaturing conditions. The first peak coeluted with intact hormone. The second eluted at a position corresponding to the carboxy-terminal fragments previously described in plasma, and the last eluted at the salt volume of the column. Microsequence analysis of the radioiodinated fragments, a method that has proved valuable for chemically defining the circulating fragments resulting from metabolism of injected hormone, showed that extracts of liver and kidney, prepared at 4 and 8 min after injection of the intact hormone, contained different fragments. The radioiodinated fragments in liver extracts were identical to those previously reported in the plasma of rats and dogs, fragments resulting principally from proteolysis between positions 33 and 34 , and 36 and 37 of the intact hormone. Although the same fragments were also present in the kidneys, they constituted less than $15 \%$ of the amount present in the liver. More than $50 \%$ of the
\end{abstract}

Pierre D'Amour was a Fellow of the Medical Research Council of Canada and is presently at Hopital St. Luc, Montreal, Canada. Gino V. Segre is a recipient of Research Career Development Award AM 00070 from the National Institute of Arthritis, Metabolism, and Digestive Diseases. Sanford I. Roth is presently Professor and Chairman, Department of Pathology, University of Arkansas for Medical Sciences, Little Rock, Ark. 72201. Requests for reprints should be addressed to Gino V. Segre, Endocrine Unit, Massachusetts General Hospital, Boston, Mass. 02114.

Received for publication 6 February 1978 and in revised form 27 July 1978. labeled renal fragments consisted of a peptide whose amino-terminal amino acid was position 39 of the intact hormone, a fragment not present in plasma. The rate of appearance of radioiodinated fragments that were chemically identical to those in plasma was more rapid in the liver than in plasma. Correlation of these chemical analyses with studies of the localization of ${ }^{125} \mathrm{I}$ by autoradiography showed that at the times when the intact hormone and the carboxy-terminal fragments comprised nearly all of the ${ }^{125}$ I-labeled moieties in the tissues, the proximal convoluted tubules of the kidney and sinusoidal lining cells of the liver, which probably are Kupffer cells, contained the highest concentration of ${ }^{125} \mathrm{I}$. Preferential localization of immunoreactive parathyroid hormone to these tissue sites also was shown by immunoperoxidase staining in studies with unlabeled hormone. Our results suggest that, unless multiple renal mechanisms are present for release of hormonal fragments, one of which releases the circulating fragments preferentially, the liver, rather than the kidney, is principally responsible for generating the carboxy-terminal fragments in plasma after injection of intact hormone, and the Kupffer cells may contain the enzymes that hydrolyze parathyroid hormone.

\section{INTRODUCTION}

Studies in anephric and uremic man (1-3) and animals $(4,5)$ and in partly hepatectomized rats $(4)$ have shown that the kidneys and the liver are principally responsible for the metabolism and(or) clearance of parathyroid hormone $(\mathrm{PTH})^{1}$ or its fragments from the circulation. The important role of these two organs in PTH

${ }^{1}$ Abbreviations used in this paper: $\mathrm{COOH}$, carboxy; $\mathrm{NH}_{2}$, amino; $\mathrm{PTH}$, parathyroid hormone; $R_{f},\left(\mathrm{~V}_{\mathrm{e}}-\mathrm{V}_{0}\right) / \mathrm{V}_{\mathrm{s}}$ $-\mathrm{V}_{0}$ ), where $\mathrm{V}_{\mathrm{e}}=$ elution volume of the sample, $\mathrm{V}_{\mathrm{s}}=$ elution volume of salt, and $\mathrm{V}_{0}=$ void volume of the column. 
metabolism has been confirmed by measurements of arteriovenous differences in immunoreactive PTH across various organ beds of intact animals $(6,7)$ and by studies with isolated, perfused livers (8) and kidneys $(9,10)$. The understanding of PTH metabolism has been complicated, however, by the finding that the functions of these two organs differ. Isolated, perfused livers and kidneys both release hormonal fragments of PTH into the perfusate $(8,9)$. Both organs remove intact hormone from the plasma in vivo (11), but only the kidney clears circulating fragments (11). Studies in our laboratory have shown that negligible concentrations of circulating fragments appear after injection of bovine [ $\left.{ }^{125} \mathrm{I}\right]$ iodo-PTH to totally hepatectomized rats, indicating that the liver probably is the dominant contributor to circulating plasma fragments. ${ }^{2}$ Despite considerable attention, however, the biologic significance of hormonal metabolism remains uncertain. Microsequence analysis of the radioiodinated fragments in the plasma of rats (12) and dogs (13) after injection of bovine [ $\left.{ }^{125} \mathrm{I}\right]$ iodo-PTH, with the automated Edman reaction, demonstrated that identical peptide bonds of PTH are hydrolyzed in both species, principally those between positions 33 and 34, and 36 and 37 of the intact sequence. The specificity of this enzymic attack, coupled with evidence for differences in hepatic and renal handling of intact hormone and its fragments, suggests that hormonal metabolism may be an important physiologic reaction, controlling the availability of biologically active hormone in the circulation.

The present studies further examine the role of various organs in the uptake and metabolism of PTH and its fragments. Specific emphasis is placed on chemically identifying the labeled fragments of the hormone extracted from liver and kidney tissue and correlating these data with localization of the hormone and its fragments in these organs by autoradiography and immunoperoxidase staining.

\section{METHODS}

Preparation of radioiodinated peptides. Intact bovine PTH was purified by gel filtration and ion-exchange chromatography as previously described (14). Bovine PTH fragment 1-34 was synthesized by solid-phase methods and purified as previously described (15). Bovine serum albumin (Fraction V) was purchased from Armour Pharmaceutical Co., Kankakee, Ill.

Iodinations were performed with $\mathrm{Na}^{125} \mathrm{I}$ or $\mathrm{Na}^{131} \mathrm{I}$ (New England Nuclear, Boston, Mass.) by modifications (16) of the method of Hunter and Greenwood (17). After iodination, hormonal preparations were initially purified by adsorption to QUSO-G-32 (Philadelphia Quartz Co., Valley Forge, Pa.), and then both hormonal preparations and the bovine serum albumin were gel-filtered as previously described (12).

Aliquots of a single preparation of bovine [125I]iodo-PTH $\left(75 \times 10^{6} \mathrm{cpm}, 200-300 \mathrm{mCi} / \mathrm{mg} \mathrm{sp}\right.$ act $)$ in $0.5 \mathrm{ml}$ of $0.05 \mathrm{M}$

${ }^{2}$ Manuscript in preparation. barbital buffer, $10 \%$ plasma vol/vol, $\mathrm{pH} 8.6$, some that also contained ${ }^{131}$ I-labeled bovine serum albumin $\left(1.25 \times 10^{6}\right.$ cpm), were quick-frozen in acetone-Dry Ice (Airco Industrial Gases, Div. of Airco Inc., Murray Hill, N. J.). Aliquots were stored for no more than $10 \mathrm{~d}$ at $-70^{\circ} \mathrm{C}$, and each aliquot was thawed only once.

Protocol for animal studies. Studies with bovine $\left[{ }^{125} \mathrm{I}\right]-$ iodo-PTH were conducted in 48 white male rats (Charles River Breeding Laboratories, Wilmington, Mass.) that weighed $266 \pm 29 \mathrm{~g}$ and were anesthetized by i.p. injection of pentobarbital sodium $(6 \mathrm{mg} / 100 \mathrm{~g})$.

Tissue and organ uptakes of the radiolabeled preparations were studied after animals received rapid injection (20-30 s), into the external jugular vein, of $0.5 \mathrm{ml}$ of a solution that contained radiolabeled intact hormone and bovine serum albumin. Five rats were sacrificed by exsanguination through the abdominal aorta at the following intervals after injection of the hormone: $2,4,6,8,12,24,48$, and $96 \mathrm{~min}$. Blood, collected in heparinized syringes, was transferred to tubes and centrifuged at $3,000 \mathrm{~g}$ for $20 \mathrm{~min}$ at $4^{\circ} \mathrm{C}$. Heart, spleen, liver, lungs, kidneys, a femur, and a sample of muscle were dissected, blotted, and weighed. A representative sample of each organ was also weighed. The total weights of bone and muscle were estimated to be 10.9 and $45.4 \%$, respectively, of the total animal weight (18). Urine was collected by bladder puncture from three animals 96 min after injection of the labeled hormone. After removal of aliquots for counting of the radioactivity, urine samples were immediately frozen in hexane-Dry Ice and then stored at $-70^{\circ} \mathrm{C}$. Triplicate $100-\mu$ l plasma samples, duplicate $50-\mu$ l samples of urines, and the portions of tissues and organs previously weighed were counted in a dual-channel well spectrometer (Packard Instrument Co., Inc., Downers Grove, IIl.). ${ }^{125} I$ and the ratio of ${ }^{131} I$ to ${ }^{125} I$ in all plasma and urine samples were calculated after correcting the ${ }^{125} \mathrm{I}$ counts for ${ }^{131} \mathrm{I}$.

The plasma volume of each rat was determined by the following equation: plasma volume (milliliters) $=$ injected dose of ${ }^{131}$ I-labeled bovine serum albumin (counts per minute)/ ${ }^{131} \mathrm{I}$-labeled bovine serum albumin (counts per minute/milliliter).

Tissue and organ uptakes of the ${ }^{125} \mathrm{I}$ were calculated with the following equation, which corrected for plasma ${ }^{125} I$ trapped in the sample: tissue or organ uptake of ${ }^{125}$ (counts per minute/total weight $)=\left(\left[{ }^{125} I\right.\right.$ in sample counted (counts per minute) $]-\left[{ }^{131} I\right.$ (counts per minute) in sample $/\left({ }^{131} I /\right.$ ${ }^{125}$ I)] $\times$ (total organ or tissue weight/sample weight).

For percent tissue or organ uptake of the injected dose, the calculation was as follows: percent tissue or organ uptake $=\left(\right.$ tissue uptake [counts per minute]/injected dose of ${ }^{125} I$ [counts per minute]) $\times 100$.

For studies in which radioactivity was extracted from organs for sequence analysis, two rats were sacrificed at each of the following time intervals after injection of $0.5 \mathrm{ml}$ that contained only bovine [125I]iodo-PTH: 4, 8, 24, and $96 \mathrm{~min}$. Details of the protocol were the same as above except that the liver and kidneys were immediately frozen in hexane-Dry Ice and then stored at $-70^{\circ} \mathrm{C}$. The amount of ${ }^{125} \mathrm{I}$ in these organs did not differ from that found in studies that quantitated the uptake of the tracer by these organs.

Additional studies were performed in 10 anesthetized, white male rats that weighed $270 \pm 10 \mathrm{~g} .4 \mathrm{~min}$ after injection of 10-50 $\mu \mathrm{g}$ of intact, unlabeled bovine PTH, the animals were sacrificed, and the kidneys and livers were removed and prepared for microscopical localization of PTH by the indirect peroxidase-labeled-antibody method of Mazurkiewicz and Nakane (19).

Procedures for organ extraction. The frozen liver and kidneys were pulverized individually to a fine powder in a mortar 
with Dry Ice. Intact bovine $\left[{ }^{131} I\right]$ iodo-PTH was then added to the frozen powder to monitor for artefactual degradation that might occur during subsequent tissue processing. The tissue was extracted at $0^{\circ} \mathrm{C}$ for 2 to $4 \mathrm{~h}$ in $6 \mathrm{M}$ guanidine hydrochloride (Heico Laboratory, Delaware Water Gap, Pa.):0.1 M EDTA:0.2 M acetic acid, pH $3.5(1 \mathrm{ml} / 300 \mathrm{mg}$ wet weight of tissue), and then heated to $85^{\circ} \mathrm{C}$ for $20 \mathrm{~min}$ to inactivate heatlabile peptidases. The extract was then centrifuged at $40,000 \mathrm{~g}$ for $1 \mathrm{~h}$ at $4^{\circ} \mathrm{C}$ on a Sorvall Centrifuge model RC-2B with SS-34 rotor (Dupont Instrument Products Div., Sorvall Operations, Wilmington, Del.). The liquid phase, between the lipid at the surface and the pellet, was recovered and gel-filtered. Less than $10 \%$ of the radioactivity, including the radioactivity in the centrifuged pellet, was lost during the extraction procedure.

For sequence analysis of samples, gel filtration of large amounts of tissue extract necessitated reducing the amount of tissue proteins in the samples. Most of the high molecular weight material was precipitated. Initially, $3 \mathrm{vol}$ of ice-cold $0.2 \mathrm{~N}$ acetic acid and a saturated solution of ammonium acetate were added $(1 \mathrm{ml} / 20 \mathrm{ml})$. After two centrifugations for $30 \mathrm{~min}$ at $40,000 \mathrm{~g}$ at $4^{\circ} \mathrm{C}$, the supernates were recovered. The pellets were counted for radioactivity and discarded. The supernates were diluted with $5 \mathrm{vol}$ of $0.2 \mathrm{~N}$ acetic acid and lyophilized twice to remove volatile salts. After reconstitution with water to restore the solution to $6 \mathrm{M}$ with respect to guanidine, the solution was gel-filtered. Reducing the protein concentration permitted gel filtration of three to four times more of the sample. Total recovery of radioactivity for these samples ranged from 65 to $80 \%$. Assessment of the bovine $\left[{ }^{131} \mathrm{I}\right]$ iodo-PTH by gel filtration assured that no degradation of the tracer had occurred.

Gel filtration. Urine, made $6 \mathrm{M}$ with respect to guanidine by addition of the salt, and duplicate tissue extracts from pools obtained at each of the times sampled were chromatographed on columns of Bio-Gel A $0.5 \mathrm{~m}$ (100-200 mesh, Bio-Rad Laboratories, Richmond, Calif.) equilibrated in and eluted with $6 \mathrm{M}$ guanidine- $\mathrm{HCl}: 0.1 \mathrm{M}$ ammonium acetate: $1 \%$ $\mathrm{vol} / \mathrm{vol}$ plasma, $\mathrm{pH}$ 6.4. In most experiments, $200-\mu \mathrm{l}$ samples were applied to columns $(1.2 \times 95 \mathrm{~cm}$, fraction size $=2 \mathrm{ml})$, and $6 \mathrm{ml}$ of samples for sequence analysis were filtered on columns $(2.5 \times 95 \mathrm{~cm}$, fraction size $=2 \mathrm{ml})$. The ${ }^{131} \mathrm{I}$ and ${ }^{125} \mathrm{I}$ in each fraction were counted, and the ${ }^{125}$ I radioactivity was corrected both for ${ }^{131} \mathrm{I}$ and for radioactive decay.

For sequence analysis, fractions in the region of the chromatogram that corresponded to the large carboxy $(\mathrm{COOH})$-terminal fragments seen in plasma samples $\left(R_{f}=V_{e}-V_{0} / V_{s}\right.$ $-V_{0}$, where $V_{e}=$ elution volume of the sample, $V_{s}=$ elution volume of salt, and $\mathrm{V}_{0}=$ void volume of the column $)\left(R_{f}=0.42\right.$ - 0.58) (12) were pooled and gel-filtered on columns $(5 \times 50$ $\mathrm{cm}$ ) of Bio-Gel P-2 (100-200 mesh), equilibrated, and eluted with $1 \mathrm{~N}$ acetic acid at $4^{\circ} \mathrm{C}$ to remove the guanidine salt. All radioactivity eluted in the void volume. Recoveries ranged from 84 to $92 \%$. The radioactive fractions were then pooled, lyophilized, frozen, and stored at $-70^{\circ} \mathrm{C}$.

Radioactivity in each peak of the chromatograms was quantitated by planimetry, and the results were expressed in terms of the total organ uptake of radioactivity.

Edman degradations. Lyophilized samples were dissolved in heptafluorobutyric acid. Degradations were performed in the Beckman model 890 (Beckman Instruments, Inc., Spinco Div., Palo Alto, Calif.) with a single-coupling, double-cleavage program (20). All procedures used for converting the anilinothiazolinone derivatives, for extracting the phenylthiohydantoin derivatives, and for identifying the radioiodinated derivatives were identical to those previously reported $(12,13)$. All samples were degraded for at least 25 cycles, and several for more than 30 cycles. The results are expressed after correction, assuming a repetitive yield of $96 \%$ for each cycle of the Edman degradation.

Histological preparation and autoradiography. The tissues from animals sacrificed at 4,8 , and 24 min after injection of bovine [ ${ }^{125}$ I] iodo-PTH were immediately fixed in Zamboni's picric acid-formaldehyde (21) or Karnovsky's paraformaldehyde-glutaraldehyde (22). Tissues in Zamboni's fixative were then dehydrated with graded ethanol solutions and dioxane before they were embedded in paraffin. Sections of 4-6 $\mu \mathrm{m}$ were mounted on slides and coated with liquid NTB-2 nuclear-tract emulsion (Eastman Kodak Co., Rochester, N. Y.). After a 1-d exposure, the autoradiographs were developed in Dektol (Eastman Kodak Co.) for $2 \mathrm{~min}$ at $28^{\circ} \mathrm{C}$. Tissues in Karnovsky's fixative were embedded in epoxy resin after the method of Luft (23). Sections of $1 \mu \mathrm{m}$ were mounted on slides and coated with liquid NTB-2 nuclear-tract emulsion diluted 1:8 with distilled water. After exposure for 1, 2, and 3 wk, the autoradiographs were developed with Dektol for 5 $\min$ at $28^{\circ} \mathrm{C}$

For immunoperoxidase localization of immunoreactive PTH, tissue fixed in Zamboni's solution was embedded in polyethylene glycol. Sections of $4 \mu \mathrm{m}$ were treated with rabbit anti-bovine-PTH antisera (R-12) at a dilution of 1:10 for $24 \mathrm{~h}$. $\mathrm{R}-12$ is a multivalent antiserum that recognizes determinants in both the amino $\left(\mathrm{NH}_{2}\right)$ - and $\mathrm{COOH}$-terminal portions of the PTH sequence (24). After the tissue was treated for $24 \mathrm{~h}$ with peroxidase-labeled goat anti-rabbit IgG (N. L. Cappel Laboratories Inc., Cochranville, $\mathrm{Pa}$.), sections were stained according to the method of Karnovsky (22). Tissue sections exposed to normal rabbit serum for $24 \mathrm{~h}$, rather than to rabbit antibovine PTH antiserum, served as controls.

\section{RESULTS}

Distribution of ${ }^{125} I$. Fig. 1 shows the disappearance of ${ }^{125}$ I from the plasma space and the uptake and subsequent disappearance of radioactivity from various or-

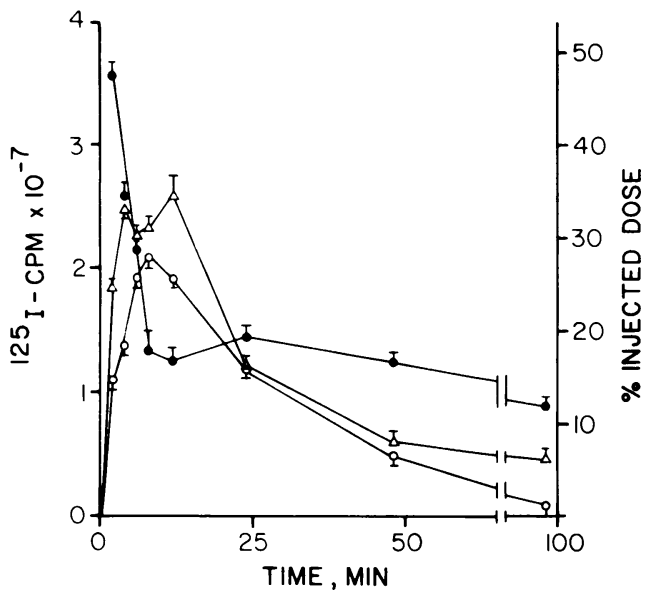

FIGURE 1 125I, contained in the estimated plasma volume and in the whole organ, is graphed with respect to the time of sampling. The left and right vertical axes represent total radioactivity and percentage of the injected dose, respectively, that were calculated to be present. The same animals were used in the studies reported in reference 12 , and the data concerning ${ }^{125} \mathrm{I}$ in the plasma is redrawn from Fig. 3 of reference 12. Total plasma volume $(\bullet-\bigcirc)$; liver $(\triangle \longrightarrow \triangle)$; kidneys $(O-O)$. Values represent mean $\pm \operatorname{SEM}(n=5)$. 


\section{LIVER KIDNEY}
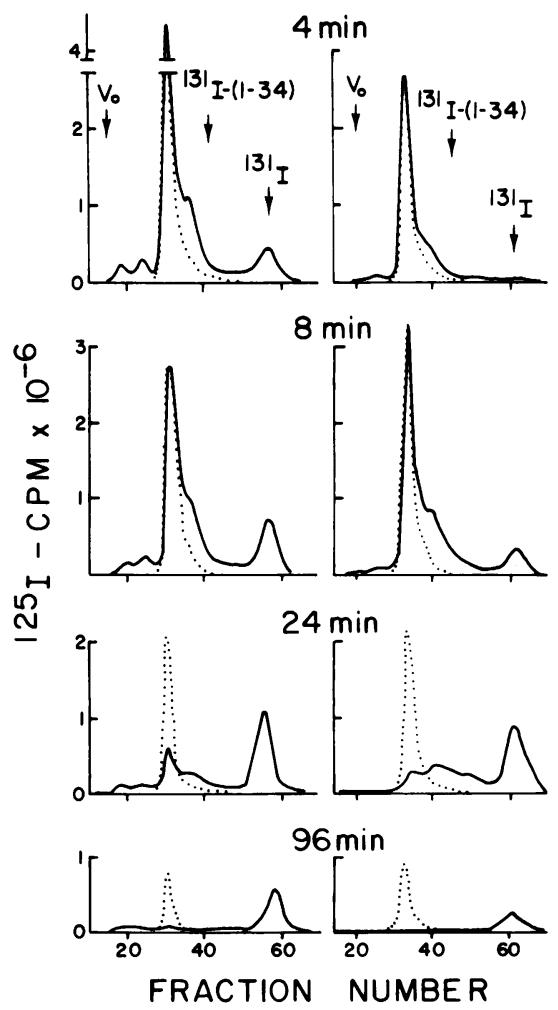

Figure 2 Gel filtration profiles of ${ }^{125} \mathrm{I}$ in extracts of kidney and liver taken at various time intervals after injection of bovine [ $\left.{ }^{125} \mathrm{I}\right]$ iodo-PTH. Chromatography was conducted on Bio-Gel A $0.5 \mathrm{~m}$. The elution position of fractions within the void volume $\left(\mathrm{V}_{0}\right)$, and the elution position of bovine PTH fragment $1-34$, and ${ }^{131} \mathrm{I}^{-}$are indicated by the arrows. The elution position of intact bovine [ $\left.{ }^{131} I\right]$ iodo-PTH is shown in the dotted line. gans and tissues. Early in the experiments, most of the ${ }^{125} \mathrm{I}$ was present in the liver, kidneys, and plasma; $77.2 \pm 6.1 \%$ (SEM) of the ${ }^{125} \mathrm{I}$ injected was distributed in these three tissue spaces at $12 \mathrm{~min}$. The ${ }^{125} \mathrm{I}$ disappears from plasma so rapidly that by $12 \mathrm{~min}$ the plasma space contained only $16.8 \pm 0.5 \%$ of the radioactivity. The liver and kidneys contained $60.4 \pm 5.8 \%$ of the radioactivity. Whereas the amount of radioactivity in the liver increased rapidly, reaching its maximum by $4 \mathrm{~min}$, and remained relatively constant $(32.3 \pm 4.7 \%$ of the injected dose) until $12 \mathrm{~min}$, the amount of radioactivity in the kidney increased more slowly, achieving a maximum at $8 \mathrm{~min}(27.8 \pm 3.9 \%)$, and thereafter decreased. Radioactivity in muscle and bone also increased, accounting for $8.9 \pm 0.9 \%$ and $6.4 \pm 0.5 \%$ of the injected dose, respectively, at $12 \mathrm{~min}$, and ${ }^{125} \mathrm{I}$ in other organs (spleen, heart, and lung) did not exceed $2 \%$ of the injected dose at any time during the $96 \mathrm{~min}$. This amount of ${ }^{125} \mathrm{I}$ is compatible with distribution of the tracer in the extracellular compartment of these tissues. Total urinary excretion of ${ }^{125} \mathrm{I}$ during the $96 \mathrm{~min}$ accounted for $10.1 \pm 2.3 \%$ of the injected dose.

As previously noted (12), the amount of ${ }^{125}$ in plasma increased between 12 and $24 \mathrm{~min}$, which reflects release back into the plasma of labeled moieties previously sequestered in the extravascular space.

Gel chromatography of the liver and kidney extracts and urine. The gel chromatograms of the liver and kidney extracts are shown (Fig. 2), and the quantity of each ${ }^{125}$ I-containing moiety, as determined by its elution position upon gel filtration, was calculated (Table I). The elution position of the principal radioactive peak $\left(R_{f}=0.37\right)$ in both the liver and the kidneys at 4 and 8 min after injection of the bovine [ $\left.{ }^{125} \mathrm{I}\right]$ iodo-PTH was coincident with the bovine $\left[{ }^{131} \mathrm{I}\right]$ iodo-PTH and pre-

TABLE I

Quantitation of the ${ }^{125}$ I in Extracts of Liver and Kidney Removed at Various Times after Injection of Bovine [ ${ }^{125}$ I] iodo-PTH as Assessed by Elution Position after Gel Filtration with Protein-Denaturing Conditions*

\begin{tabular}{|c|c|c|c|c|c|c|c|c|}
\hline \multirow[b]{2}{*}{$\min$} & \multicolumn{4}{|c|}{ Liver } & \multicolumn{4}{|c|}{ Kidney } \\
\hline & 4 & 8 & 24 & 96 & 4 & 8 & 24 & 96 \\
\hline & \multicolumn{4}{|c|}{$\%$} & \multicolumn{4}{|c|}{$\%$} \\
\hline Total $\ddagger$ & 33.7 & 30.8 & 16.2 & 6.4 & 18.4 & 28.2 & 16.1 & 3.1 \\
\hline Void $\S$ & 2.6 & 2.2 & 1.4 & 0.9 & 0.6 & 1.0 & 0.4 & 0.1 \\
\hline Intact hormone" & 20.2 & 14.3 & 2.6 & 0.4 & 14.8 & 15.5 & 1.5 & 0.1 \\
\hline Fragments & 7.3 & 8.4 & 3.8 & 1.0 & 2.4 & 9.0 & 6.4 & 0.5 \\
\hline Salt volume & 3.6 & 5.9 & 8.4 & 4.1 & 0.6 & 2.7 & 7.8 & 2.4 \\
\hline
\end{tabular}

* Data are expressed as a mean of two gel-filtration experiments for pools of samples at each time interval.

$\$$ Total = percent of the injected dose of ${ }^{125}$ I contained in the organ.

$\S$ The amount of radioactivity in each peak (Fig. 2) of the chromatogram was quantitated by planimetry and expressed as a percent of the injected dose of ${ }^{125}$ I.

|| 125I co-eluting with bovine [ $\left.{ }^{131} \mathrm{I}\right]$ iodo-PTH is assumed to be intact hormone. 
sumably is intact hormone. The amount of intact hormone, expressed as a percentage of the injected dose (mean of experiments in two rats), remained nearly constant in the kidney at these two time intervals, whereas, in the liver, it fell from 20.2 to $14.3 \%$. By $24 \mathrm{~min}$, intact hormone in both the liver and kidney accounted for only $4.1 \%$ of the injected dose, and, by 96 min, intact hormone was scarcely detectable in either organ.

A second, discrete radioactive peak $\left(R_{f}=0.49\right)$ was discernible by $4 \mathrm{~min}$ in extracts of both the liver and kidneys, accounting for 7.3 and $2.4 \%$ of the injected dose of radioactivity. Extracts of both organs prepared 8 min after injection of bovine [ ${ }^{125}$ I] iodo-PTH contain the greatest amount of this material: $8.4 \%$ and $9.0 \%$ of the injected radioactivity appeared in this form in the liver and kidneys, respectively. At later times, the pattern of radioactivity eluting later than intact hormone was more diffuse, particularly in the kidney extract. In addition, by $24 \mathrm{~min}$ the total amount of these fragments in both organs had decreased to $10.2 \%$ of the injected dose. Radioactivity eluting at the position of ${ }^{131} \mathrm{I}$ in the liver and kidneys increased from 3.6 and $0.6 \%$ at $4 \mathrm{~min}$ to a maximum at $24 \mathrm{~min}$ of 8.4 and $7.8 \%$. At the later times studied, the predominant form of radioactivity eluted at the salt volume in both liver and kidneys. Over $99 \%$ of the ${ }^{125} \mathrm{I}$ in the urine eluted at the salt volume; neither intact hormone nor the labeled COOH-terminal fragments were detected.

Sequence analysis of the radiolabeled fragments. Automated Edman degradations were performed on extracts of both liver and kidney prepared 4 and $8 \mathrm{~min}$ after injection of the radioiodinated hormone. Gel chromatograms that resulted from gel filtration of 6-ml samples of these tissue extracts on columns $(2.5 \times 95 \mathrm{~cm})$ were identical to those shown (Fig. 2) when differences in the amount of radioactivity and size of fractions were considered. Fractions between $R_{f}$ of 0.42 and 0.58 were subjected to sequence analysis (Fig. 3). In the liver, specific $\left[{ }^{125} \mathrm{I}\right]$ monoiodotyrosyl and $\left[{ }^{125} \mathrm{I}\right]$ diiodotyrosyl radioactivity were released at cycles 7 and 10 of the degradation, corresponding to cleavage of the intact hormone between residues 36 and 37 , and 33 and 34 . At $8 \mathrm{~min}$, release of specific [ $\left.{ }^{125} \mathrm{I}\right]$ monoiodotyrosyl and [125I]diiodotyrosyl radioactivity were also apparent after 3 cycles and particularly after 1 cycle of degradation, corresponding to cleavage of the intact hormone between residues 40 and 41 , and 42 and 43 . Although chemically identical, radioiodinated fragments were also present in the kidney, albeit in considerably smaller amounts, the major fragment in the kidney at both 4 and $8 \mathrm{~min}$ resulted from proteolysis between residues 38 and 39. Fragments with position 39 of the intact hormone as their $\mathbf{N H}_{2}$-terminal residue have not been detected in the circulation of the rat (12).

Tissue localization. Localization of the ${ }^{125} \mathrm{I}$ dif-

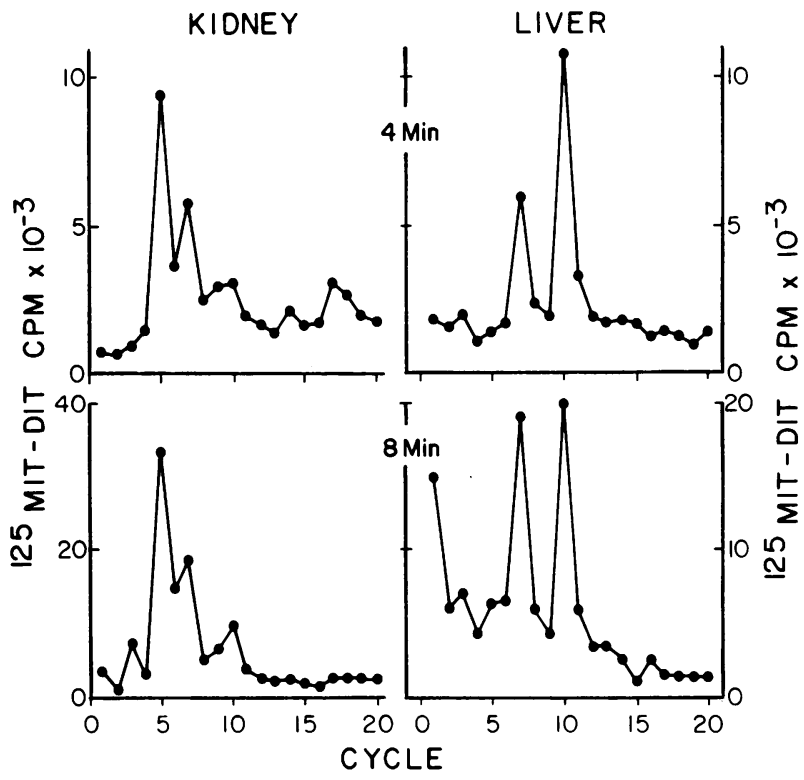

FIGURE 3 Specific iodotyrosyl radioactivity released at each cycle of the Edman degradation from pools of fractions $\left(R_{f}=0.42-0.58\right)$ of the chromatogram that correspond to the ${ }^{125}$ I-containing fragments in extracts of the liver and kidney.

fered with respect to the time that the sample was obtained after injection of bovine [ $\left.{ }^{125} \mathrm{I}\right]$ iodo-PTH. At 4 min, the autoradiographs showed grains confined, predominantly, to the tubular pole of Bowman's space (Fig. 4A) and to the lumenal surface of proximal convoluted tubules (Fig. 4B). Strikingly fewer grains were seen over other tubular segments, the interstitium, and the tubular and glomerular capillaries. Only some of the proximal tubules appeared to contain ${ }^{125} \mathrm{I}$. By $8 \mathrm{~min}$, the label continued to be predominantly localized to the lumen and the apical regions of the proximal tubular cells, although the distribution of the label appeared to be slightly more diffuse than it was at $4 \mathrm{~min}$. By 24 min, labeling persisted in the proximal tubular lumens, and was less intense and distributed even more diffusely in proximal tubule cells. Some grains were also seen over the interstitium and tubular capillaries (figures not shown).

In the liver, the early localization $(4 \mathrm{~min})$ of ${ }^{125} \mathrm{I}$ was confined largely to sinusoidal lining cells, presumably Kupffer cells (Fig. 5). Grains over hepatic cells were no greater than background. By $8 \mathrm{~min}$, hepatic cells contained more grains, although still less than Kupffer cells, and, by $24 \mathrm{~min}$, the grains were distributed in a uniform fashion over both hepatic and Kupffer cells (figure not shown).

With indirect immunoperoxidase staining, the reaction product was confined predominantly to the lumens and apical portions of the proximal convoluted tubules at 4 min after injection of the hormone (Fig. 6). Stain- 


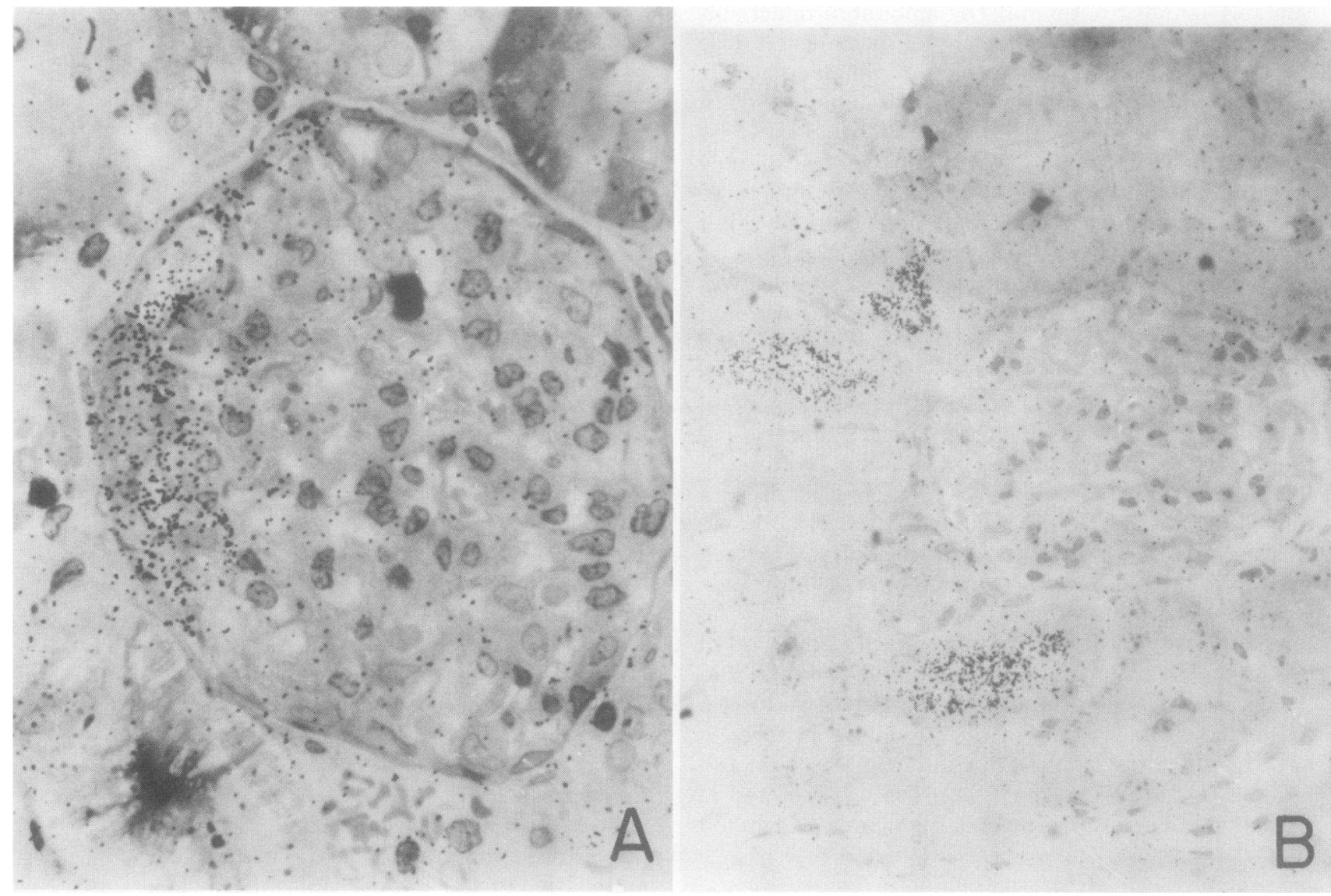

FIGURE 4 Autoradiographs of $1-\mu \mathrm{m}$ sections of rat kidney removed $4 \mathrm{~min}$ after intravenous injection of bovine [125I]iodo-PTH, demonstrating early localization principally to (A) tubular pole of Bowman's space; (B) lumenal pole of proximal tubule cells. Sections were embedded in epoxy and stained with toluidine blue.

ing of less intensity was also seen over the interstitium and glomerular capillaries.

At $4 \mathrm{~min}$, the reaction product localized in sinusoidal lining cells of the liver, presumably Kupffer cells, whereas hepatocytes appeared to be free of staining (Fig. 7). Control slides of both kidney and hepatic tissue were free of the reaction product.

\section{DISCUSSION}

The results of these studies extend previous observations $(1-11,25-28)$ indicating that the liver and kidneys play critical roles in the metabolism and(or) clearance of PTH.

Uptake of bovine [125I]iodo-PTH occurs rapidly in both the liver and kidneys after intravenous administration of the hormone. As shown in Table I, the amount of intact hormone taken up by the liver and kidneys was as high or higher by $4 \mathrm{~min}$, the earliest sample analyzed, than it was at any later time. When expressed in terms of wet weight of the total organs, the amount in the liver was greater by a factor of 1.5 . The amount of intact hormone in the liver decreased throughout the remainder of the experiment, whereas, in the kidney, the amount appeared to remain constant until 8 min after injection and decreased thereafter.

${ }^{125}$ I-labeled $\mathrm{COOH}$-terminal fragments were present in the liver and kidney at the earliest time examined, 4 min after injection. The amount of this material in these organs was somewhat greater than previously reported by Neuman et al. (28). However, the differences may be because of the time at which samples were obtained. Our results and those of Neuman et al. (28) agree that at times soon after injection of the hormone, there is more of the large $\mathrm{COOH}$-terminal fragment in the liver than in the kidney and, at later times, the amount of this material in the kidney exceeds that in the liver.

The chemical nature of the iodinated fragments in these two organs is of interest for several reasons. We 


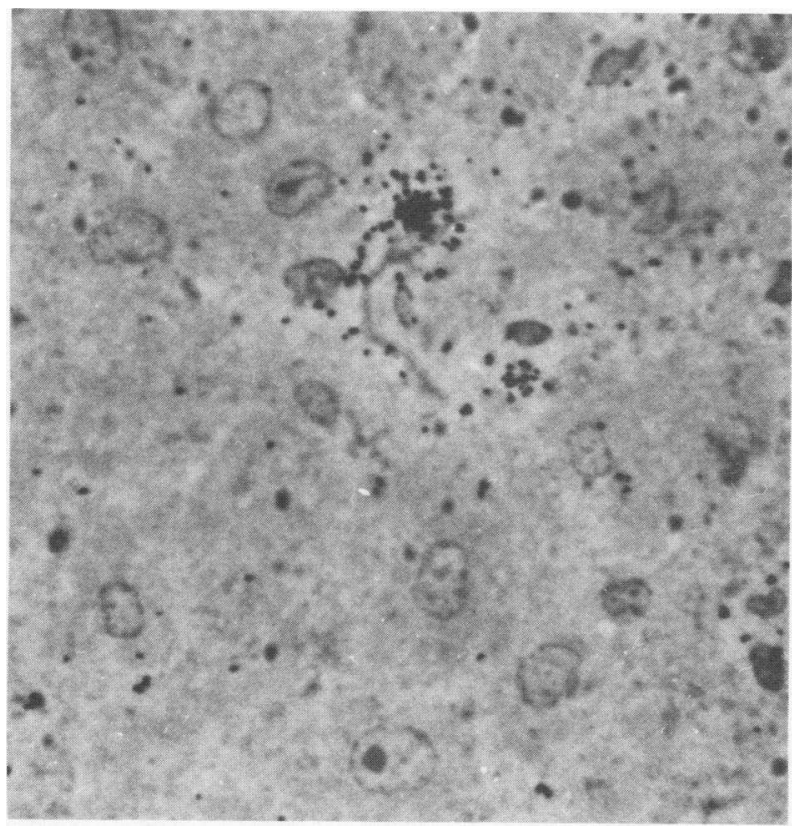

Figure 5 Autoradiograph of $1-\mu \mathrm{m}$ sections of rat liver removed 4 min after intravenous injection of bovine [ $\left.{ }^{125} \mathrm{I}\right]$ iodoPTH. The grains are principally confined to areas of spindleshaped Kupffer cells located between the large polyhedral hepatocytes. Sections are embedded in epoxy and stained with toluidine blue.

previously reported that in the rat (12) and in the dog (13) the major radioiodinated fragments in plasma obtained shortly after injection of bovine [ $\left.{ }^{125} \mathrm{I}\right]$ iodo-PTH

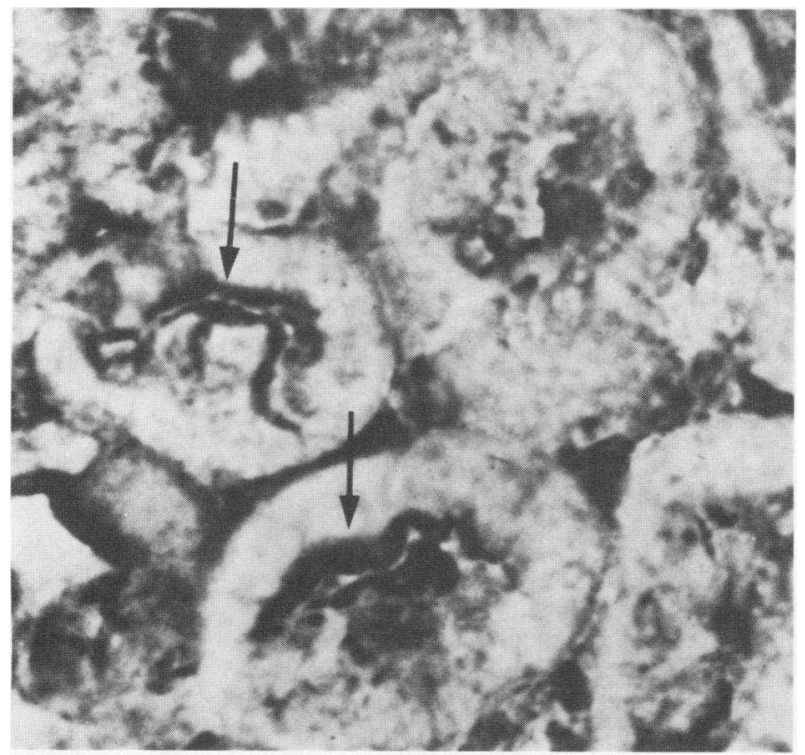

FIGURE 6 Light micrograph of the immunoperoxidase reaction on $4-\mu \mathrm{m}$ sections of rat kidney removed $4 \mathrm{~min}$ after injection of $20 \mu \mathrm{g}$ of bovine PTH. Localization of immunoreactive PTH is largely limited to the lumens and lumenal surfaces of proximal convoluted tubule cells.

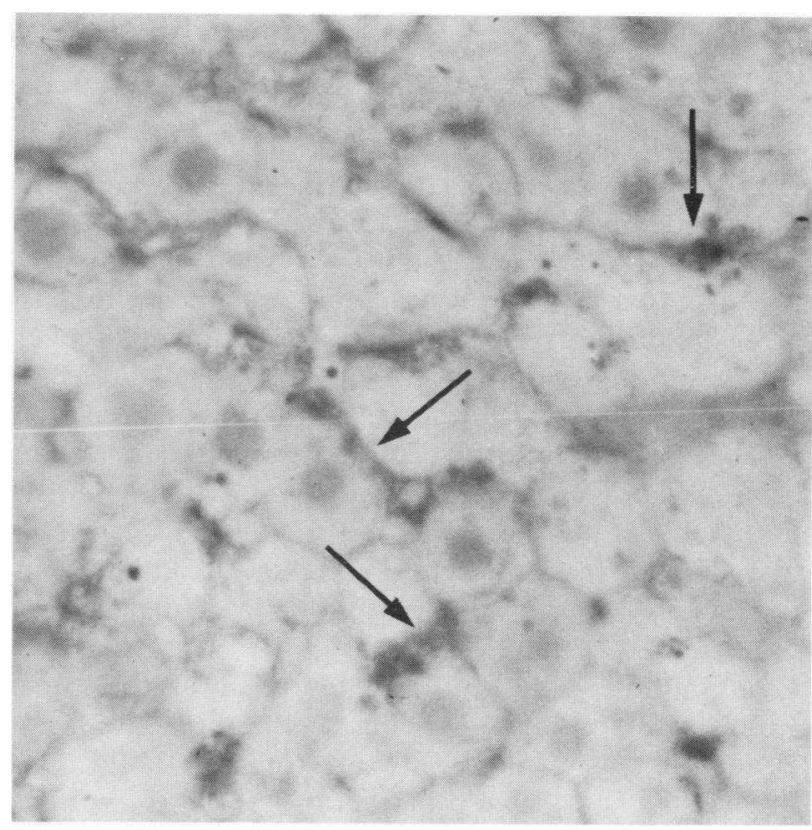

FIGURE 7 Light micrograph of the immunoperoxidase reaction on a $4-\mu \mathrm{m}$ section of rat liver removed $4 \mathrm{~min}$ after injection of $20 \mu \mathrm{g}$ of bovine PTH. Staining is principally limited to the perisinusoidal areas. Hepatic cords are outlined by the positively stained Kupffer cells.

were those with positions 34 and 37 of the intact hormone as their $\mathrm{NH}_{2}$-terminal residues. Whereas these circulating fragments, containing the middle and $\mathrm{COOH}$-terminal portions of the sequence, were identical with those found in extracts of liver obtained at the same time intervals after injection, the fragments seen in plasma and liver differ strikingly from those found in the kidneys. Although both these fragments were also present in the kidney $4 \mathrm{~min}$ after injection of the intact hormone, the kidneys contained only $15 \%$ of the amount in the liver. The major labeled, $\mathrm{COOH}$ terminal fragment in extracts of the kidney has residue 39 of the intact hormone at its $\mathrm{NH}_{2}$-terminus. This fragment has not been found in plasma. Therefore, unless several different renal pathways are involved in the metabolism of these COOH-terminal fragments, these data also indicate that the renal contribution to the circulating fragments of PTH is probably small.

An issue of particular interest is whether the fragments found in the liver are the result of hepatic metabolism of intact hormone, or are fragments that are generated elsewhere and are removed from plasma. The data of Martin et al. (11) suggest that the liver does not remove $\mathrm{COOH}$-terminal fragments from the circulation. The rate of appearance of labeled fragments was more rapid in the liver, reaching a maximum by $4 \mathrm{~min}$ after injection, than in plasma, and the relative content of these fragments was several times greater in the liver than in plasma at all comparable 
times sampled. Our previous data showed that the peak plasma concentration of labeled fragments in these animals occurred 12 minutes after injection of bovine [125I]iodo-PTH and was only $2.5 \%$ of the injected dose (12). Therefore, because no significant renal contribution to the circulating fragment pool appears likely (vide supra), our data are most consistent with the hypothesis that circulating fragments result, principally at least, from metabolic processes occurring in the liver. It is important to note, however, that these studies are concerned only with the peripheral metabolism of PTH. They do not directly further our understanding of the relative contributions of peripheral metabolism of intact secreted hormone and secretion of hormonal fragments by the parathyroid glands to the heterogeneity of endogenous PTH in plasma, an issue that remains unsettled (16, 29-32).

Autoradiographic studies show that at the times when over $80 \%$ of the radioactivity in the kidney is either in intact hormone or in the large $\mathrm{COOH}$-terminal fragments, ${ }^{125}$ I localized most intensely in the tubular pole of Bowman's space and in the apical, or lumenal, portions of cells in the initial segments of the proximal convoluted tubules. ${ }^{125}$ I does not appear in concentrations above background in renal segments other than the proximal convoluted tubules, and only a portion of these tubular segments contains a large number of grains. These findings are confirmed by the immunoperoxidase-staining technique and suggest that uptake of PTH by the kidney is largely limited to the portion of the proximal convoluted tubule near the glomerulus. The presence of grains in Bowman's space at the earliest time plus the absence of detectable amounts of bovine $\left[{ }^{125} \mathrm{I}\right]$ iodo-PTH in the urine are most consistent with the view that the hormone is filtered by the glomerulus and virtually totally taken up by the proximal tubule. At later times, when the ${ }^{125} \mathrm{I}$ is predominantly in the form of free ${ }^{125} \mathrm{I}$ or iodotyrosine or, perhaps, small peptides that elute at the salt volume of the column upon gel filtration, the radioactive label is more diffusely localized throughout the proximal tubule cells and the adjacent interstitium. The difference seen between our results and those reported by Nordquist and Palmieri (27) may well be because of times at which their samples were taken, which were at least $1 \mathrm{~h}$ after continuous infusion of PTH.

Autoradiography localized ${ }^{125}$ I to the Kupffer cells of the liver at early times, when over $80 \%$ of the radioactivity in the liver is in either intact hormone or the COOH-terminal fragments. This was confirmed with the immunoperoxidase technique. Although these findings have not been reported for PTH, localization of insulin (33-35), glucagon (36), growth hormone (3739 ), luteinizing hormone, and follicle-stimulating hormone $(40,41)$, human chorionic gonadotropin $(42)$, and prolactin (43) to Kupffer cells has been previously noted. At later times, when the label is, principally, in very small molecular entities, the localization of ${ }^{125} I$ is more diffusely distributed throughout hepatic and Kupffer cells, and is similar to the localization reported by Neuman et al. (28). The close correlation between our results, with a ${ }^{125}$ I-labeled hormone probably having low biologic potency, and those reported by Neuman et al. (28), with biologically active ${ }^{125}$ I-labeled PTH, coupled with our previous results showing that the kinetics of metabolism of bovine [125I]iodo-PTH and unlabeled hormone were similar, if not identical (13), and our current data showing that localization of ${ }^{125}$ I-labeled and unlabeled preparations are identical, indicate that the metabolism of the radioiodinated PTH used in these studies accurately reflects the metabolism of unlabeled hormone.

Several studies have indicated that the liver is of primary importance in the proteolysis of PTH to fragments $(3,8,11,28)$. The early and preferential localization of PTH to sinusoidal lining cells of the liver and the chemical evidence that hepatic and plasma hormonal fragments are identical suggest that these cells contribute in a major fashion to the peripheral metabolism of the hormone. An alternative explanation might be that cleavage of the hormone takes place in hepatic cells and the reaction products undergo phagocytosis by these cells. Current evidence, however, indicates that this is unlikely. At early times, when the ${ }^{125} \mathrm{I}$ in the liver is contained in intact hormone, not in labeled fragments, the ${ }^{125} \mathrm{I}$ is present virtually exclusively in these cells, rather than in hepatocytes. Second, we recently reported that when isolated Kupffer cells are incubated in vitro, they metabolize both bovine ${ }^{125}$ I] iodo-PTH and unlabeled hormone to fragments that are, respectively, chemically and immunochemically identical to those found in plasma in vivo (44). Whether macrophages other than those found in the liver contribute to PTH metabolism is not known. Further studies in vitro will be necessary to analyze the properties and role of the cleavage enzymes, including particularly the proteolytic activity of hepatic and other macrophages.

\section{ACKNOWLEDGMENTS}

We thank Mr. M. D. Ernst and Mr. P. C. Dee for technical assistance.

This work was supported in part by grants AM 11794 and 04501 from the National Institute of Arthritis, Metabolism, and Digestive Diseases; by grant CA 18616 from the National Cancer Institute; by a grant from the John A. Hartford Foundation; and by contract NAS 9-11011 from the National Aeronautics and Space Administration.

\section{REFERENCES}

1. Melick, R. A., and T. J. Martin. 1969. Parathyroid hormone metabolism in man: effect of nephrectomy. Clin. Sci. (Oxf.). 37: 667-674. 
2. Berson, S. A., and R. S. Yalow. 1968. Immunochemical heterogeneity of parathyroid hormone in plasma. J. Clin. Endocrinol. Metab. 28: 1037-1047.

3. Silverman, R., and R. S. Yalow. 1973. Heterogeneity of parathyroid hormone: clinical and physiologic implication. J. Clin. Invest. 52: 1958-1971.

4. Fang, V. S., and A. H. Tashjian, Jr. 1972. Studies on the role of the liver in the metabolism of parathyroid hormone. I. Effects of partial hepatectomy and inactivation of the hormone with tissue homogenates. Endocrinology. 90: 1177-1184.

5. Martin, T. J., R. A. Melick, and M. de Luise. 1969. The effect of nephrectomy on the metabolism of labeled parathyroid hormone. Clin. Sci. (Oxf.). 37: 137-142.

6. Singer, F. R., G. V. Segre, J. F. Habener, and J. T. Potts, Jr. 1975. Peripheral metabolism of bovine parathyroid hormone in the dog. Metab. Clin. Exp. 24: 139-144.

7. Hruska, K. A., R. Kopelman, W. E. Rutherford, S. Klahr, and E. Slatopolsky. 1975. Metabolism of immunoreactive parathyroid hormone in the dog: the role of the kidney and the effects of chronic renal disease. J. Clin. Invest. 56: $39-48$.

8. Canterbury, J. M., L. A. Bricker, G. S. Levey, R. L. Kozlovskis, E. Ruiz, J. E. Zull, and E. Reiss. 1975. Metabolism of bovine parathyroid hormone: immunochemical and biological characteristics of fragments generated by liver perfusion. J. Clin. Invest. 55: 1245-1253.

9. Hruska, K. A., K. Martin, P. Mennes, A. Greenwalt, C. Anderson, S. Klahr, and E. Slatopolsky. 1977. Degradation of parathyroid hormone and fragment production by the isolated perfused dog kidney: the effect of glomerular filtration rate and perfusate $\mathrm{Ca}^{++}$concentrations. J. Clin. Invest. 60: 501-510.

10. Martin, K. J., K. A. Hruska, J. Lewis, C. Anderson, and E. Slatopolsky. 1977. The renal handling of parathyroid hormone: role of peritubular uptake and glomerular filtration. J. Clin. Invest. 60: 808-814.

11. Martin, K., K. Hruska, A. Greenwalt, S. Klahr, and E. Slatopolsky. 1976. Selective uptake of intact parathyroid hormone by the liver; differences between hepatic and renal uptake. J. Clin. Invest. 58: 781-788.

12. Segre, G. V., P. D'Amour, and J. T. Potts, Jr. 1976. Metabolism of radioiodinated bovine parathyroid hormone in the rat. Endocrinology. 99: 1645-1652.

13. Segre, G. V., H. D. Niall, R. T. Sauer, and J. T. Potts, Jr. 1977. Edman degradation of radioiodinated parathyroid hormone: application to sequence analysis and hormone metabolism in vivo. Biochemistry. 16: 2417-2427.

14. Keutmann, H. T., G. D. Aurbach, B. F. Dawson, H. D. Niall, L. D. Deftos, and J. T. Potts, Jr. 1971. Isolation and characterization of the bovine parathyroid isohormones. Biochemistry. 10: 2779-2787.

15. Tregear, G. W., J. van Rietschoten, E. Greene, H. T. Keutmann, H. D. Niall, B. Reit, J. A. Parsons, and J. T. Potts, Jr. 1973. Bovine parathyroid hormone: minimum chain length of synthetic peptide required for biological activity. Endocrinology. 93: 1349-1353.

16. Segre, G. V., J. F. Habener, D. Powell, G. W. Tregear, and J. T. Potts, Jr. 1972. Parathyroid hormone in human plasma: immunochemical characterization and biological implications. J. Clin. Invest. 51: 3163-3672.

17. Hunter, W. M., and F. C. Greenwood. 1962. Preparation of iodine-131 labelled human growth hormone of high specific activity. Nature (Lond.). 194: 495-496.

18. Skelton, H. 1927. The storage of water by various tissues of the body. Arch. Intern. Med. 40: 140-152.

19. Mazurkiewicz, J. E., and P. K. Nakane. 1972. Light and electron microscopic localization of antigens in tis- sues embedded in polyethylene glycol with a peroxidase-labeled antibody method.J. Histochem. Cytochem. 20: 969-974.

20. Edman, P., and E. Begg. 1967. A protein sequenator. Eur. J. Biochem. 1: 80-91.

21. Stefanini, M., C. De Martino, and L. Zamboni. 1967. Fixation of ejaculated spermatozoa for electron microscopy. Nature (Lond.). 216: 173-174.

22. Karnovsky, M. J. 1965. A formaldehyde-glutaraldehyde fixative of high osmolality for use in electron microscopy. J. Cell Biol. 27: 137A-138A. (Abstr.)

23. Luft, J. H. 1961. Improvements in epoxy resin embedding methods. J. Biophys. Biochem. Cytol. 9: 409-414.

24. Segre, G. V., and J. T. Potts, Jr. 1976. Immunological comparisons of two synthetic human parathyroid hormone-(1-34) peptides. Endocrinology. 98: 1294-1301.

25. de Kretser, D. M., T. J. Martin, and R. A. Melick. 1970. The radioautographic localization of ${ }^{125}$ I-labeled bovine parathyroid hormone. J. Endocrinol. 46: 507-510.

26. Zull, J. E., and D. W. Repke. 1972. The tissue localization of tritiated parathyroid hormone in thyroparathyroidectomized rats. J. Biol. Chem. 246: 2195-2199.

27. Nordquist, R. E., and G. M. A. Palmieri. 1974. Intracellular localization of parathyroid hormone in the kidney. Endocrinology. 95: 229-237.

28. Neuman, W. F., M. W. Neuman, P. J. Sammon, W. Simon, and K. Lane. 1975. The metabolism of labeled parathyroid hormone. III. Studies in rats. Calcif. Tissue Res. 18: 251-261.

29. Habener, J. F., D. Powell, T. M. Murray, G. P. Mayer, and J. T. Potts, Jr. 1971. Parathyroid hormone secretion and metabolism in vivo. Proc. Natl. Acad. Sci. U. S. A. 68: 2986-2991.

30. Flueck, J. A., F. P. Di Bella, A. J. Edis, J. M. Kehrwald, and C. D. Arnaud. 1977. Immunoheterogeneity of parathyroid hormone in venous effluent serum from hyperfunctioning parathyroid glands. J. Clin. Invest. 60: 1367-1375.

31. Mayer, G. P., J. A. Keaton, J. G. Hurst, and J. F. Habener. 1977. Effects of plasma calcium concentration on the relative proportion of hormone and carboxyl fragment in parathyroid venous blood. Program, Abstracts, of the 59th Annual Meeting of the Endocrine Society. Endocrinology. 100(Suppl.): 234. (Abstr. 355)

32. Hanley, D. A., K. Takatsuki, and L. M. Sherwood. 1977. Evidence for release of fragments of parathyroid hormone during "perifusion" of bovine parathyroid glands in vitro. Program, Abstracts, of the 59th Annual Meeting of the Endocrine Society. Endocrinology. 100 (Suppl.): 184. (Abstr. 255)

33. Stein, O., and J. Gross. 1959. The localization and metabolism of $I^{131}$ insulin in the muscle and some other tissues of the rat. Endocrinology. 65: 707-716.

34. Worthington, W. C., Jr., D. J. Jones, and M. G. Buse. 1964. Autoradiographic study of insulin distribution in the rat with special reference to elastic tissue. Endocrinology. 74: 914-924.

35. Elgee, N. J., and R. N. Williams. 1954. Degradation of insulin- $\mathrm{I}^{131}$ by liver and kidney in vivo. Proc. Soc. Exp. Biol. Med. 87: 352-355.

36. Narahara, H. T., N. B. Everett, B. S. Simmons, and R. H. Williams. 1958. Metabolism of insulin- $\mathrm{I}^{131}$ and glucagon- $\mathrm{I}^{131}$ in the kidney of the rat. Am. J. Physiol. 192: $227-231$.

37. Collipp, P. J., J. R. Patrick, C. Goodheart, and S. A. Kaplan. 1966. Distribution of tritium labeled human growth hormone in rats and guinea pigs. Proc. Soc. Exp. Biol. Med. 121: 173-177. 
38. de Kretser, D. M., K. J. Catt, H. G. Burger, and G. C. Smith. 1969. Radioautographic studies on the localization of ${ }^{125}$ I-labeled human luteinizing and growth hormone in immature male rats. J. Endocrinol. 43: 105-110.

39. Mayberry, H. E., J. L. Van den Brande, J. J. Van Wyk, and W. J. Waddell. 1971. Early localization of ${ }^{125} \mathrm{I}-$ labeled human growth hormone in adrenals and other organs of immature hypophysectomized rats. Endocrinology. 88: 1309-1317.

40. Vilar, O., B. Alvarez, O. Davidson, and R. E. Mancini. 1964. Incorporation by the kidney of fluorescent pituitary hormone. J. Histochem. Cytochem. 12: 621-627.

41. Rajaniemi, H., and T. Vanha-Perttula. 1972. Specific receptor for LH in the ovary: evidence by autoradiog- raphy and tissue fractionation. Endocrinology. 90: $1-9$.

42. Rajaniemi, H., and T. Vanha-Perttula. 1973. Distribution of HCG and asialo-HCG in the mouse: quantitative and radioautographic studies. Horm. Res. (Basel). 4: $177-189$.

43. Rajaniemi, H., A. Oksanen, and T. Vanha-Perttula. 1974. Distribution of ${ }^{125}$ I-prolactin in mice and rats: studies with whole-body and microautoradiography. Horm. Res. (Basel). 5: 6-20.

44. Segre, G. V., A. Perkins, L. A. Witters, and J. T. Potts, Jr. 1978. Proteolysis of parathyroid hormone by isolated Kupffer cells. Clin. Res. 26: 533A. (Abstr.) 